\title{
OPTIMIZATION OF DESIGN OF MIXED FLOW CENTRIFUGAL PUMP IMPELLER USING CFD
}

\author{
Krishna Kumar Yadav ${ }^{1}$, Karun Mendiratta ${ }^{2}$, V.K. Gahlot ${ }^{3}$ \\ ${ }^{1}$ Assistant Professor, Department of Mechanical Engineering, NIET, Greater Noida, Uttar Pradesh, India \\ ${ }^{2}$ Assistant Professor, Department of Mechanical Engineering, NIET, Greater Noida, Uttar Pradesh, India \\ ${ }^{3}$ Professor, Department of Civil Engineering, MANIT, Bhopal, Madhya Pradesh, India
}

\begin{abstract}
Centrifugal pumps are widely used hydraulic machines, irrespective of the fact that their performance is generally not very good. So, turning them into more efficient machines is quite a challenge. The performance of a centrifugal pump is highly dependent on its geometrical parameters and its vane profile. In order to analyze the flow through complex systems like centrifugal pumps, Computation fluid dynamics (CFD) has been used. This work aims to study the performance analysis of a centrifugal mixed flow pump designed to deliver $0.25 \mathrm{~m}^{3} / \mathrm{s}$ of water with a head of $20 \mathrm{~m}$ at a speed of $1450 \mathrm{rpm}$ using ANSYS CFX (ver.14.0). PTC Creo (ver. 2.0) has been used to model the pump unit. The performance of the pump was first determined using the existing vane angles and thickness of the blade then, the inlet vane angle, the outlet vane angle along with the thickness of the blade has been varied to analyze the pump's performance. The results show that for an initial inlet angle $21.08^{\circ}$, outlet angle $16.28^{\circ}$ and blade thickness as $10 \mathrm{~mm}$, the efficiency of the pump was $84 \%$. However, the efficiency of pump rises to $89.19 \%$ for the optimized angles and blade thickness.
\end{abstract}

Keywords: Computational Fluid Dynamics (CFD) Analysis, Mixed Flow Pump, Overall Efficiency.

\section{INTRODUCTION}

A pump is a machine which is used to circulate the liquid within a piping system and also to raise the pressure of the liquid. A pump can further be defined as a machine which uses several energy transformations to increase the pressure of the liquid. A mixed flow pump is an example of a combined flow i.e. radial and axial flow pump. Here, the liquid enters axially and leaves radially through the impeller. These pumps have a large number of applications in the field of irrigation, water supply, fire fighting, and many other industries. However, their performance is generally not so good. Losses like: leakage, hydraulic, disc friction and mechanical losses play a very important role in evaluating the performance of a mixed flow pump. In order to reduce the energy consumption, the performance of the pump must be improved.

As discussed in the previous work by Yadav and Gahlot [1], Hydraulic loss can be minimized by changing the blade angle, number of blades, and by using smooth surfaces. Leakage loss can be reduced by using seal and inter-stage bushings. Disc frictional losses can be avoided by controlling the leakage between two surfaces and the surface roughness. Mechanical losses, which arise due to friction, can be minimized by the use of ball bearings, roller bearings and/or seals.

Manikandan et al. [2] observed that the leakage loss almost contributes to $7 \%$ of the total flow in mixed flow pumps. Gahlot and Nyiri [3] in their work have suggested the step by-step design procedures for Francis, Radial, and Mixed flow pumps.
Gundale et al. [4] analyzed and verified the performance of a centrifugal pump at the best efficiency point. Bacharoudis et al. [5] studied the influence of outlet blade angle on pump performance through CFD simulation. It was observed that as the outlet blade angle increases, the performance curve becomes smoother. The gain in the head developed by the pump was more than $6 \%$, when the outlet blade angle was increased from $20^{\circ}$ to $50^{\circ}$. Chaudhari et al. [6] too analyzed the performance of mixed flow impeller with the help of CFD. It was seen that the head of the impeller improved when the inlet angle, outlet angle and number of blades were changed.

Manivannan et al. [7] analyzed the mixed flow impeller through CFD. It was seen that when the inlet and outlet blade angle were changed, mixed flow impeller had the best efficiency. Kim et al. [8] analyzed the performance of a pump using CFD and RSM. It was observed that outlet blade angle affected the efficiency and head of the impeller the most. As the outlet angle increased, head increased but the efficiency decreased. Nataraj et al. [9] analyzed eight virtual models of impeller using Taguchi's approach to enhance the performance of a centrifugal pump.

Rajendran et al. [10] studied the flow pattern, pressure distribution in blade passage, blade loading and pressure plots for an impeller of a centrifugal pump by using ANSYS-CFX. Urankar et al. [11] used Walter K Jekat method and error triangle method for impeller and volute design. Performance of the designed model was analyzed in CFX at different flow rates. It was observed that the efficiency increased when a little twist to leading edge of the vane was applied. 
From the present literature, it can be observed that the performance of a mixed flow pumps hugely depends upon on its active pump components i.e. its impeller and the volute casing, since the energy is generated through fluid flow in the pump from these. However, not much work has been reported on the effect of blade thickness on pump performance. This research aims to analyze the effect of three parameters namely, inlet angle, outlet angle, and thickness of the blade on the performance of mixed flow pump, and also to find the optimal values for these parameters to enhance the overall efficiency of the pump.

\section{PUMP SPECIFICATIONS}

\subsection{Impeller Geometry}

The performance of a mixed flow pump is greatly affected by its impeller geometry. Mostly by the blade profile parameters like inlet angle, outlet angle, length of the blade and thickness of the blade. In the present work, a pump has been designed with its specifications as shown in Table-1. Detailed study of the impeller geometric features has been done.

Table-1: Design specification of pump

\begin{tabular}{|c|c|}
\hline Design & Specifications \\
\hline Flow rate $\left(\mathrm{m}^{3} / \mathrm{s}\right)$ & 0.25 \\
\hline Head $(\mathrm{m})$ & 20 \\
\hline Rotating speed $(\mathrm{rpm})$ & 1450 \\
\hline
\end{tabular}

In order to investigate the individual or combined effects of these geometric features on the flow and impeller performance, parameterization was also performed by reducing the number of controlling geometric variables. The values of which are given in Table-2.

Table-2: Geometrical features of the impeller

\begin{tabular}{|c|c|}
\hline Parameter & Size \\
\hline Inlet diameter $\left(\mathrm{D}_{1}\right)$ & $169 \mathrm{~mm}$ \\
\hline Outlet diameter $\left(\mathrm{D}_{2}\right)$ & $307 \mathrm{~mm}$ \\
\hline Number of blades & 8 \\
\hline Blade width at inlet $\left(\mathrm{b}_{1}\right)$ & $112 \mathrm{~mm}$ \\
\hline Blade width at outlet $\left(\mathrm{b}_{2}\right)$ & $64.5 \mathrm{~mm}$ \\
\hline Blade thickness $(\mathrm{t})$ & $10 \mathrm{~mm}$ \\
\hline
\end{tabular}

\section{METHOD FOR CONSTRUCTING THE VANE}

\section{SHAPE}

\subsection{Point by Point Method}

Now, let us consider a small segment $\mathrm{DD}_{1}$ of stream line $\mathrm{A}_{1} \mathrm{~A}_{2}$ lying on the meridional plane. But, the real length of $\mathrm{DD}_{1}$ is EE1 (as shown in the Fig-2: Side elevation), represented by the segment $\mathrm{FF}_{1}$ in plan. In triangle $\mathrm{EE}_{1} \mathrm{G}$, the $\angle \mathrm{G}$ is a right angle and $\angle \mathrm{E}_{1} \mathrm{EG}$ equals to $\beta$. Then;

$$
E G=\frac{E_{1} G}{\tan \beta}=\frac{d e}{\tan \beta}
$$

And, as the projection of segment EG is HF. So;

$$
\begin{gathered}
H F=r d \theta=\frac{d e}{\tan \beta} \\
d \theta=d e \frac{d e}{r \tan \beta}
\end{gathered}
$$

Integrating above eqn. and multiplying by $180 / \pi$, gives the central angle $(\theta)$ in degrees i.e.

$$
\frac{180}{\pi} \int_{0}^{e} \frac{d e}{r \tan \beta}
$$
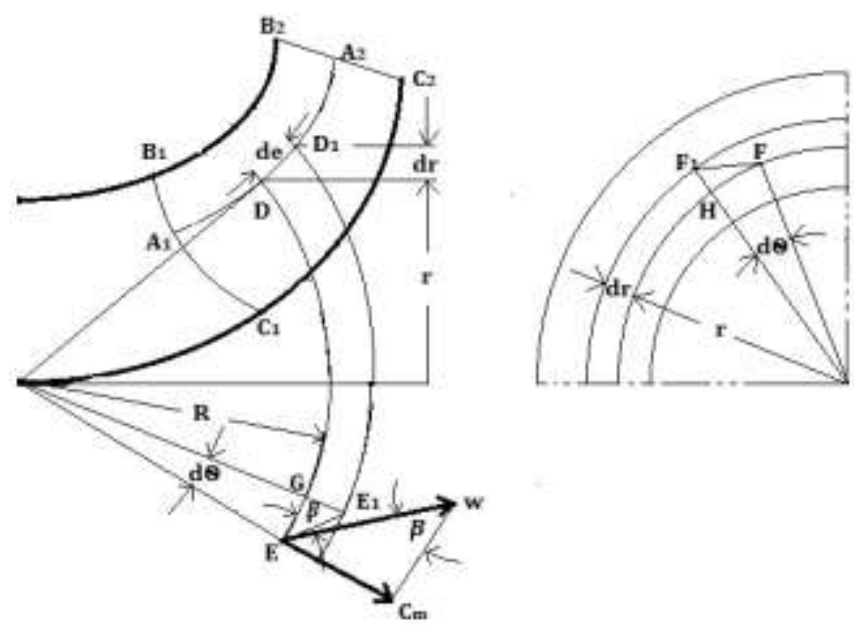

Fig-2: Point by Point method [1]

The values of $\theta$ and e are measured from a point starting from the inlet edge. As the relation between $\beta, \mathrm{r}$ and $\mathrm{e}$ is unknown in a form of an equation, integration is carried out numerically, assuming finite increments $(\Delta \mathrm{e})$. After determining the values of central angle $(\theta)$ and radius (r) at each point, a stream line is plotted in the plan view. Similarly, other stream lines are determined.

\subsection{Effect of Finite Thickness of Blades}

In actual, the impeller consists of a definite number of blades of finite thickness resulting in reduction of the area available for the fluid flow. In order to determine the influence of blades on the velocity field, let us consider two cylindrical surfaces of radii $r_{I}$ and $r_{I I}$, which are concentric with the impeller blade as show in Fig-3. In centrifugal pumps (where, inlet and outlet edges of blade are parallel to impeller axis) these surfaces are found close to the vane edges.

Let, pitch of the blade be $t_{1}$ on a circle of radius $r$, and projection of blade thickness $S_{1}$ (in the direction tangential to its circumference) to be $S_{\mathrm{u} 1}$. Then, from the continuity eqn; 


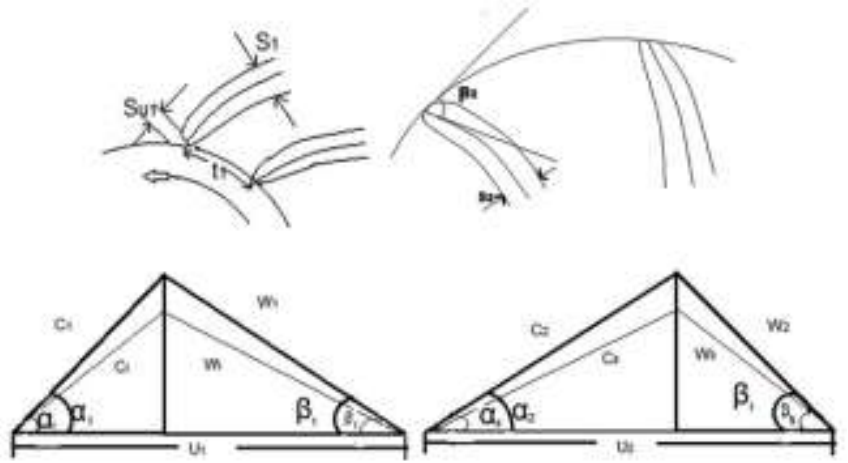

Fig-3: Velocity Triangles at Inlet and Outlet

$$
C_{m 1}=C_{m I} \frac{t_{1}}{t_{1}-S_{u 1}} \quad\left[\text { Where, } t_{1}=\frac{\pi d_{1}}{z}\right]
$$

$$
\text { And, } S_{u 1}=\frac{S_{1}}{\operatorname{Sin} \beta_{1}}
$$

$\mathrm{C}_{\mathrm{I}}$ and $\mathrm{C}_{\mathrm{m} 1}$ are the velocities of fluid just before the entry into the impeller.

Now, for a given pump geometry, $\mathrm{t}_{1}$ and $\mathrm{S}_{\mathrm{u} 1}$ are constants

$$
C_{m 1}=\emptyset_{1} C_{m I}
$$

From inlet velocity triangle (Fig.3), we find that;

$$
\begin{gathered}
\mathrm{C}_{\mathrm{mI}}=\mathrm{C}_{\mathrm{I}} \operatorname{Sin} \alpha_{\mathrm{I}}=\mathrm{W}_{\mathrm{I}} \sin \beta_{\mathrm{I}} \\
\text { And, } \mathrm{C}_{\mathrm{m} 1}=\mathrm{C}_{1} \operatorname{Sin}^{\prime}{ }_{1}=\mathrm{W}_{1} \sin \beta_{1}
\end{gathered}
$$

It is recommended that the blades at inlet should be tapered and/or rounded off, to reduce the effect of blade thickness. The velocity distribution at the impeller outlet is based on an assumption that $\mathrm{C}_{\mathrm{u} 2}$ (the peripheral component of absolute velocity $\mathrm{C}$ ), does not vary while passing through a surface of radius $r_{2}$ to surface of $r_{I I}$. At the outlet, sharpening of blade tips results in a gradual reduction of flow velocity i.e. from $\mathrm{C}_{\mathrm{m} 2}$ to $\mathrm{C}_{\mathrm{mII}}$. So, from the outlet velocity triangle (Fig-3);

$$
\begin{gathered}
C_{m I I}=C_{m 2} \frac{t_{2}-S_{u 2}}{t_{2}} \\
C_{\mathrm{mII}}=\frac{\mathrm{C}_{\mathrm{m} 2}}{\emptyset_{2}}
\end{gathered}
$$

Where, $\mathrm{C}_{\mathrm{II}}$ and $\mathrm{C}_{\mathrm{m} 2}$ are the velocities of fluid at the exit of the impeller.

The model of designed mixed flow impeller is shown in Fig1.

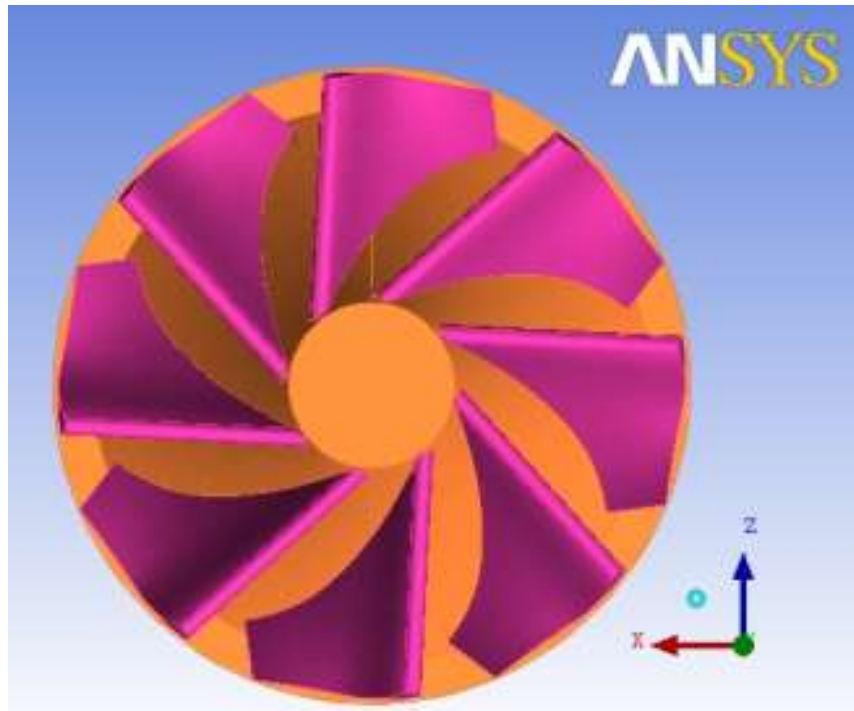

Fig-1: Model of Mixed Flow Impeller

\section{METHODS TO CALCULATE VOLUTE CASING}

\subsection{Principle of Constant Moment of Momentum}

This principle states that the moment of momentum remains constant at different sections, which can be expressed as;

$$
\mathrm{M}=\mathrm{C}_{\mathrm{u}} \mathrm{r}=\mathrm{C}_{\mathrm{u} 1} \mathrm{r}=\text { constant }
$$

\subsection{Principle of Constant Mean Velocity}

The discharge at any section of the volute can be obtained by;

$$
Q_{\varnothing}=\frac{Q * \emptyset^{\circ}}{360^{\circ}}
$$

And, Area of volute at any section can be obtained by;

$$
A_{\varnothing}=\frac{Q_{\varnothing}}{C_{3}}=\frac{Q \times \varnothing^{\circ}}{360^{\circ} \times C_{3}}
$$

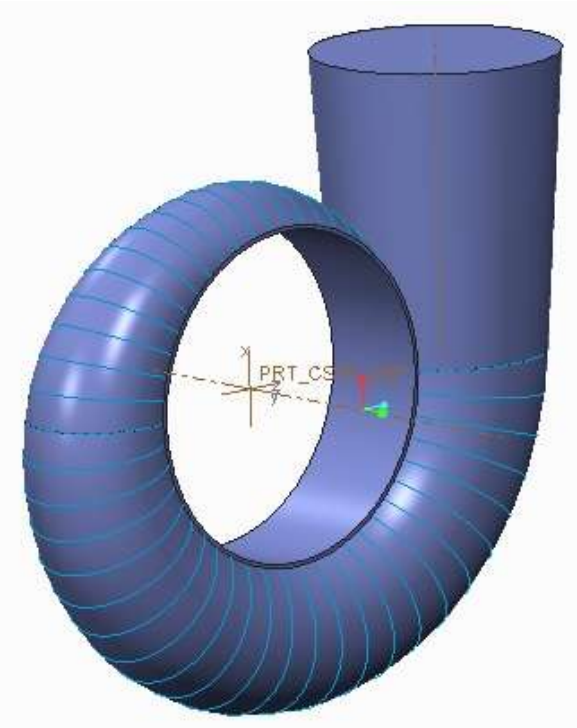

Fig-4: Model of casing 


\section{MESHING OF PUMP ASSEMBLY}

The final mesh of the pump assembly was generated using ANSYS. The corresponding model is shown in Fig.5. Meshing data with total number of elements and nodes are given in Table-3.

Table-3: Mesh information of pump assembly

\begin{tabular}{|c|c|c|c|c|}
\hline $\begin{array}{c}\text { Total } \\
\text { elements }\end{array}$ & $\begin{array}{c}\text { Total } \\
\text { nodes }\end{array}$ & TRI_3 & TETRA_4 & LINE_2 \\
\hline 6271500 & 1054300 & 178146 & 6085320 & 8134 \\
\hline
\end{tabular}

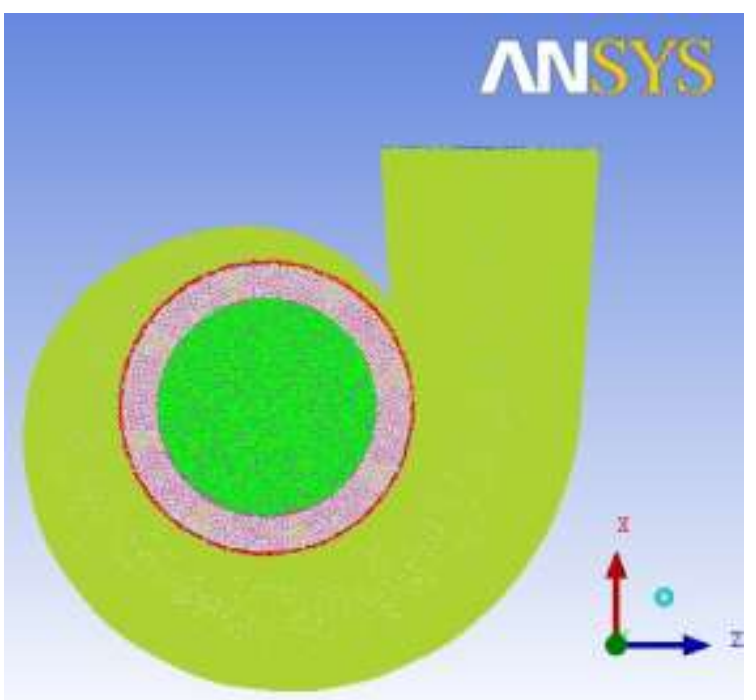

Fig-5: Meshing of pump in ANSYS

\section{BOUNDARY CONDITIONS}

This numerical computation is based on steady-state condition with the following boundary conditions: Mixed flow pump impeller domain is considered as a rotating frame of reference with the rotational speed of $1450 \mathrm{rpm}, 1$ atm. pressure at the inlet, and $0.25 \mathrm{~m}^{3} / \mathrm{s}$ discharge at the outlet The working fluid is taken as water at $25^{\circ} \mathrm{C}$. k- $\varepsilon$ turbulence model with turbulence intensity of $5 \%$ is considered.

\subsection{Velocity Stream Contour}

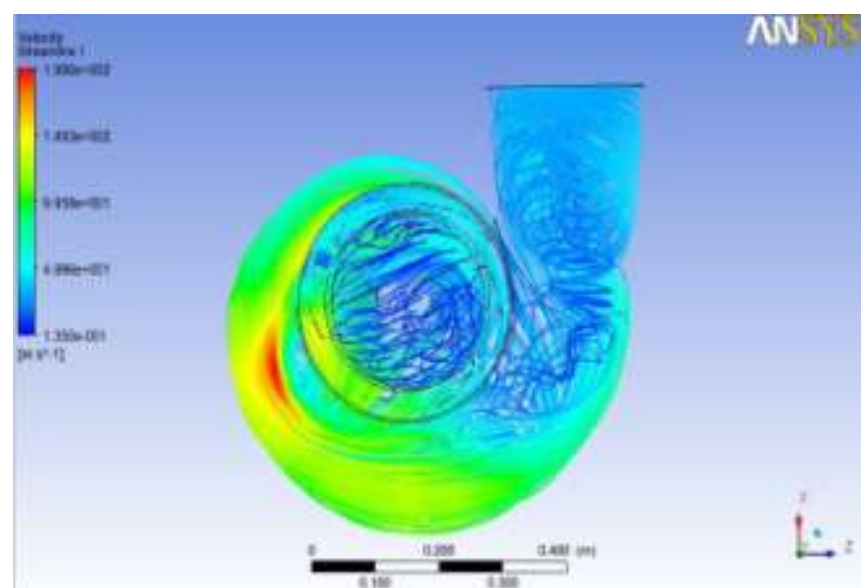

Fig-6: Velocity Stream Contour

\subsection{Pressure Contour}

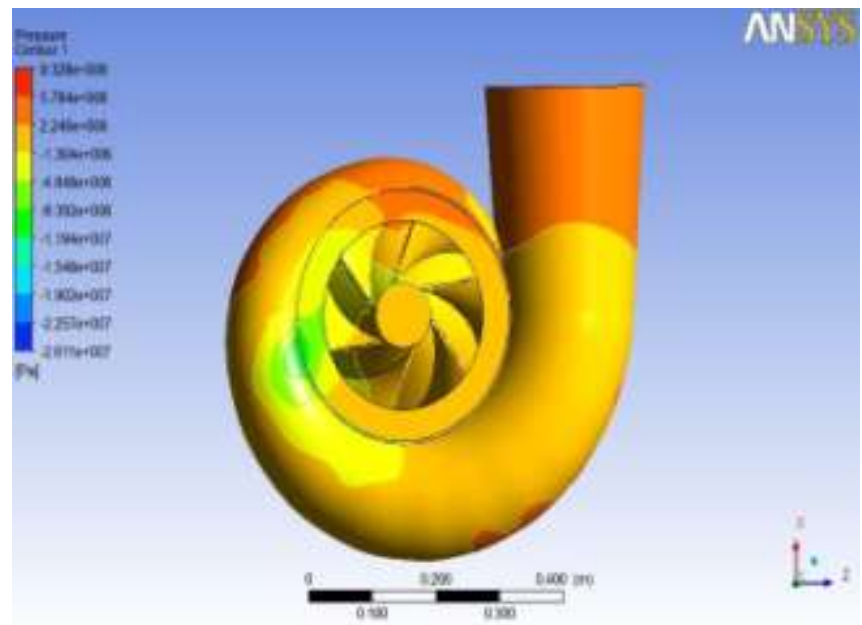

Fig.7: Pressure Contour

\section{RESULTS}

Inlet power (IP) can be calculated as;

$$
\begin{array}{cc}
\mathrm{IP}= & 2 \pi \mathrm{NT} / 60 * 1000 \\
\Rightarrow & (2 \pi * 1450 * 388.122) / 60 * 1000 \\
\Rightarrow & 58.934 \mathrm{KW}
\end{array}
$$

And, Outlet power (OP) can be calculated as;

$$
\begin{aligned}
\mathrm{OP} & =\left(\mathrm{P}_{0}-\mathrm{P}_{\mathrm{i}}\right) * \mathrm{Q} / 1000 \\
\Rightarrow & (215916.8-17900.8)^{*} 0.25 / 1000 \\
& \Rightarrow 49.504 \mathrm{KW}
\end{aligned}
$$

So, Overall efficiency $=($ Outlet power $/$ Input power $)$

$$
\begin{aligned}
& \Rightarrow 49.504 / 58.934 \\
& \Rightarrow 0.84
\end{aligned}
$$

\section{OPTIMIZATION OF RESULTS}

\subsection{Optimization of Outlet Blade Angle, Inlet Blade}

\section{Angle \& Blade thickness}

Table-4: Vane angles $\left(\beta_{1}, \beta_{2}\right)$ and Blade thickness $(\mathrm{t})$ for modified impeller

\begin{tabular}{|c|c|c|c|}
\hline Impeller & $\begin{array}{c}\text { Inlet } \\
\text { angle, } \boldsymbol{\beta}_{\mathbf{1}} \\
\text { (deg) }\end{array}$ & $\begin{array}{c}\text { Outlet } \\
\text { angle, } \boldsymbol{\beta}_{\mathbf{2}} \\
\text { (deg) }\end{array}$ & $\begin{array}{c}\text { Blade } \\
\text { thickness, } \mathbf{~} \\
\text { (mm) }\end{array}$ \\
\hline Impeller 1 & 20.16 & 16.62 & 5 \\
\hline Impeller 2 & 20.16 & 16.62 & 10 \\
\hline Impeller 3 & 20.16 & 16.62 & 15 \\
\hline Impeller 4 & 21.08 & 16.28 & 5 \\
\hline Impeller 5 & 21.08 & 16.28 & 10 \\
\hline Impeller 6 & 21.08 & 16.28 & 15 \\
\hline Impeller 7 & 22.14 & 16.20 & 5 \\
\hline Impeller 8 & 22.14 & 16.20 & 10 \\
\hline Impeller 9 & 22.14 & 16.20 & 15 \\
\hline
\end{tabular}




\subsection{Results from Optimization}

Table-5: Impeller efficiency

\begin{tabular}{|c|c|c|c|}
\hline Impeller & $\begin{array}{c}\text { Inlet } \\
\text { power } \\
\text { (KW) }\end{array}$ & $\begin{array}{c}\text { Outlet } \\
\text { power } \\
\text { (KW) }\end{array}$ & $\begin{array}{c}\text { Efficiency } \\
(\%)\end{array}$ \\
\hline Existing & 58.934 & 49.504 & 84.00 \\
\hline Impeller 1 & 61.054 & 54.460 & 89.19 \\
\hline Impeller 2 & 60.120 & 52.906 & 88.00 \\
\hline Impeller 3 & 59.006 & 51.689 & 87.59 \\
\hline Impeller 4 & 58.055 & 50.507 & 86.99 \\
\hline Impeller 5 & 59.400 & 51.203 & 86.20 \\
\hline Impeller 6 & 58.540 & 49.759 & 85.00 \\
\hline Impeller 7 & 59.100 & 50.589 & 85.59 \\
\hline Impeller 8 & 59.680 & 50.728 & 85.00 \\
\hline Impeller 9 & 55.450 & 46.024 & 83.00 \\
\hline
\end{tabular}

Table-6: Existing and Optimum vane angles, and blade thickness

\begin{tabular}{|c|c|c|c|}
\hline $\begin{array}{c}\text { Impeller } \\
\text { design }\end{array}$ & $\begin{array}{c}\text { Inlet angle, } \\
\boldsymbol{\beta}_{\mathbf{1}}(\mathbf{d e g})\end{array}$ & $\begin{array}{c}\text { Outlet } \\
\text { angle, } \boldsymbol{\beta}_{\mathbf{2}} \\
(\mathbf{d e g})\end{array}$ & $\begin{array}{c}\text { Blade } \\
\text { thickness, } \mathbf{t} \\
(\mathbf{m m})\end{array}$ \\
\hline Existing & 21.08 & 16.28 & 10 \\
\hline Optimum & 20.16 & 16.62 & 5 \\
\hline
\end{tabular}

\subsection{Efficiency Vs Mass Flow Rate}

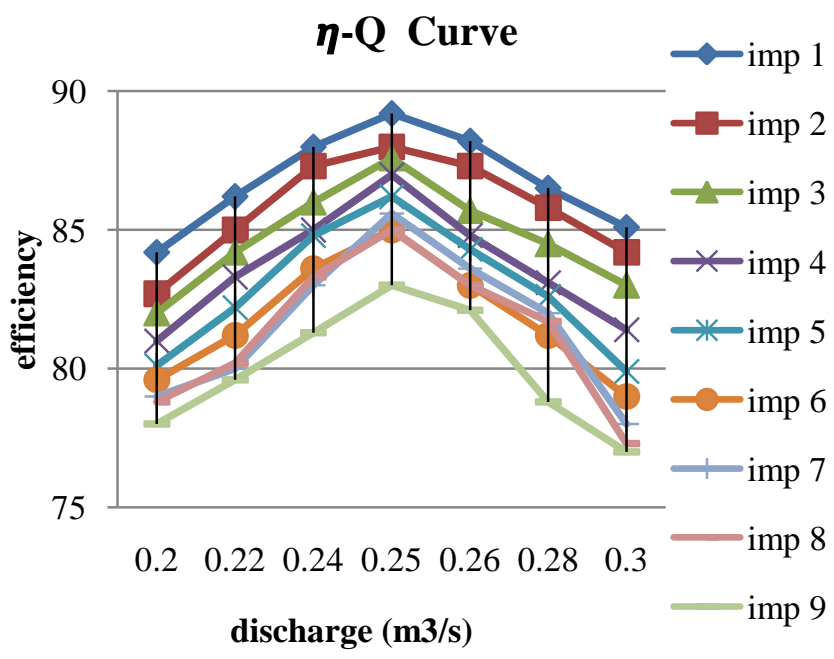

Fig-8: Efficiency Vs mass flow rate

\section{CONCLUSION}

Based on the detailed design and CFD analysis of mixed flow impeller, following conclusions can be derived:

1. The improvement in performance of mixed flow pump can be simulated by increasing the outlet blade angle, decreasing the inlet blade angle and blade thickness.

2. Optimum efficiency was obtained at an inlet angle $\left(\beta_{1}\right)$ of $20.16^{\circ}$, outlet angle $\left(\beta_{2}\right)$ of $16.62^{\circ}$, and blade thickness $(\mathrm{t})$ of $5 \mathrm{~mm}$ for Impeller 1 .

3. It has also been observed that the overall efficiency of mixed flow pump at optimum values increased by $5.81 \%$.

\section{REFERENCES}

[1]. Yadav, K. K., \& Gahlot, V. K. (2015). "Performance improvement of mixed flow pump impeller through CFD analysis", International Journal of Research in Engineering and Technology, 4(7), pp.243-247.

[2]. Manikandan, J., Senthil, V., \& Nagarajan, S. (2012). "Performance Evaluation of Mixed Flow Pump using Computational Fluid Dynamics", European Journal of Scientific Research, 80(4), pp.479-486.

[3]. Gahlot, V. K., \& Nyiri, A. (1993). "Impeller Pumps, Theory and Design", M.A.C.T, Bhopal, Madhya Pradesh, India.

[4]. Gundale, V. A., \& Patil, S. A. (2012). "Improvement in the Design of Radial type Vertical Submersible open well pumps impeller using CFD", International Journal of Engineering Research and Industrial Applications, 5(2), pp.99-108.

[5]. Bacharoudis, E. C., Filios, A. E., Mentzos, M. D., \& Margaris, D. P. (2008). "Parametric study of a centrifugal pump impeller by varying the outlet blade angle", Open Mechanical Engineering Journal, 2, pp.75-83.

[6]. Chaudhari, S. C., Yadav, C. O., \& Damor, A. B. (2013). "A comparative study of mix flow pump impeller CFD analysis and experimental data of submersible pump", International Journal of Research in Engineering and Technology, 1(3), pp.57-64.

[7]. Manivannan, A. (2010). "Computational fluid dynamics analyses of a mixed flow pump impeller", International Journal of Engineering, Science and Technology, 2(6), pp.200-206.

[8]. Kim, J.H., Oh, K. T., Pyun, K.B., Kim, C. K., Choi, Y. S., \& Yoon, J. Y. (2012). "Design optimization of a centrifugal pump impeller and volute using computational fluid dynamics", 26th IAHR Symposium on Hydraulic Machinery and Systems, 15, pp.1-9.

[9]. Nataraj, M. \& Arunachalam, V. P. (2006). "Optimizing impeller geometry for performance enhancement of a centrifugal pump using the Taguchi quality concept", Proceedings of the Institution of Mechanical Engineers, Part A: Journal of Power and Energy, 220(7), pp.765-782.

[10]. Rajendran, S. \& Purushothaman, K. (2012). "Analysis of a centrifugal pump impeller using ANSYS-CFX", International Journal of Engineering Research and Technology, 1(3), pp.1-6.

[11]. Urankar, S., Shivashankar, D. H., \& Gupta, S. (2012). "Design and CFD analysis of single stage, end suction, radial flow centrifugal pump for mine dewatering application", International Journal of Research in Engineering and Applied Sciences, 2(2), pp.6-18.

\section{BIOGRAPHIES}

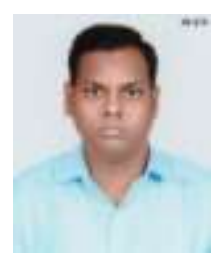

Krishna Kumar Yadav, Assistant Professor, Mechanical Department, NIET, Greater Noida 


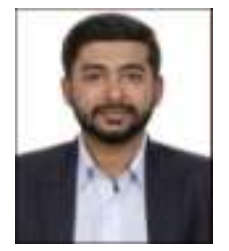

Karun Mendiratta, Assistant Professor, Mechanical Department, NIET, Greater Noida

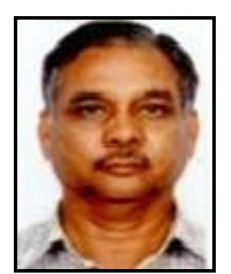

V. K. Gahlot. Professor, Civil Department, MANIT, Bhopal. 